\title{
Manipulation of Plant Cells by Cyst and Root-Knot Nematode Effectors
}

\author{
Tarek Hewezi and Thomas J. Baum \\ Department of Plant Pathology and Microbiology, lowa State University, Ames 50011, U.S.A.
}

Submitted 7 May 2012. Accepted 29 June 2012.

\begin{abstract}
A key feature of sedentary plant-parasitic nematodes is the release of effector proteins from their esophageal gland cells through their stylets into host roots. These proteinaceous stylet secretions have been shown to be crucial for successful parasitism by mediating the transition of normal root cells into specialized feeding sites and by negating plant defenses. Recent technical advances of purifying mRNA from esophageal gland cells of plant-parasitic nematodes coupled with emerging sequencing technologies is steadily expanding our knowledge of nematode effector repertoires. Host targets and biological activities of a number of nematode effectors are continuously being reported and, by now, a first picture of the complexity of sedentary nematode parasitism at the molecular level is starting to take shape. In this review, we highlight effector mechanisms that recently have been uncovered by studying the host-pathogen interaction. These mechanisms range from mediating susceptibility of host plants to the actual triggering of defense responses. In particular, we portray and discuss the mechanisms by which nematode effectors modify plant cell walls, negate host defense responses, alter auxin and polyamine signaling, mimic plant molecules, regulate stress signaling, and activate hypersensitive responses. Continuous molecular characterization of newly discovered nematode effectors will be needed to determine how these effectors orchestrate host signaling pathways and biological processes leading to successful parasitism.
\end{abstract}

The endoparasitic root-knot (Meloidogyne spp.) and cyst (Globodera and Heterodera spp.) nematodes are sedentary parasites of roots of a wide range of crop plants. In contrast to migratory ectoparasitic and endoparasitic nematodes, which feed on mostly unmodified root cells throughout their parasitic stages, the sedentary endoparasitic life styles of cyst and rootknot nematodes demand close and prolonged biotrophic interactions with their host plants. Successful interactive relationships with host cells lead to the formation of feeding cells that are maintained as the sole nutritive source for parasitic nematode life stages. The feeding cells induced by cyst nematodes (syncytia) and root-knot nematodes (giant cells) are formed through massive physiological and morphological modifications of root cells resulting in enlarged, multinucleate, and metabolically active feeding sites. These modifications are mediated, at least in part, through stylet secretions, which are

Corresponding author: Thomas J. Baum; E-mail:tbaum@iastate.edu

(C) 2013 The American Phytopathological Society produced in the nematode esophageal glands. These glands, along with the nematode mouth spear (stylet), are obvious adaptations to parasitism of phytonematodes. The esophageal glands consist of three large secretory cells, two subventral and one dorsal, that are connected to the esophageal lumen through complex valves that control exocytotic secretion release. Secretions from both types of gland cells have been shown to be released through the stylet (Hussey 1989; Hussey and Mims 1990). Although secretory activity can be observed in both gland cell types during the early stage of infection of root penetration, migration, and feeding site initiation, the subventral glands appear more active during these times. However, during the sedentary stages, when nematodes start feeding, mostly secretions from the dorsal gland cell are active (Hussey and Mims 1990). These stylet secretions are the products of genes that are expressed exclusively in the nematode's esophageal gland cells and are considered the genetic determinants of nematode parasitism and, hence, were called parasitism genes (Davis et al. 2004; Hussey 1989), although the current nomenclature prefers the term effector gene. The term "effector" has been recently defined as all pathogen proteins that alter hostcell structure and functions regardless of whether these alterations facilitate infection or trigger defense responses (Hogenhout et al. 2009). Here, we will use "effector" to signify nematode secretions that facilitate nematode parasitism, including but not limited to invasion, migration, and feeding site formation, as well as those that are associated with triggering defense responses and immunity. Although the definite modes of action of the majority of nematode effectors remain elusive, recent research efforts revealed some of their vital roles in nematode parasitism. In this review, we will briefly discuss effector identification and then elaborate on the mechanisms by which nematode effectors facilitate nematode parasitism through interaction with host plant proteins and interference with defense responses.

\section{Effector identification.}

Nematode effector proteins are synthesized in the esophageal glands and secreted into host cells and tissues through the stylet, although other potential sources of origin also have been discussed (Perry 1996). Consequently, the three esophageal gland cells have been targeted extensively to identify secretory proteins using a number of different technical approaches (Davis et al. 2004). Of all approaches, microaspiration of the esophageal gland cell contents from parasitic nematodes has proven, thus far, to be the most powerful and straightforward approach to identify effector gene candidates (Davis et al. 2004, 2008). More recently, an even more direct technique has been developed, in which whole individual esophageal gland cells are 
isolated and used for mRNA isolation and next-generation sequencing. This approach has proven successful for a large number of phytonematode taxa (Maier et al. 2013). Combining the ability to quickly identify and isolate esophageal gland cells from phytonematodes with the current and emerging sequencing technology will, indeed, expand our knowledge of nematode effector repertoires and infer the evolution of parasitism across nematode genera. Coupled with the increasing availabilities of nematode genome sequences (Abad et al. 2008; Opperman et al. 2008), it is foreseeable that complete effector repertoires of nematode species or even subspecific nematode strains will be uncovered in the not-so-distant future.

\section{Translocation and subcellular localization.}

Translocation of nematode effector proteins into the host plant to render the plant susceptible to the nematode has to be a key determinant of parasitism. Plant-parasitic nematodes use their stylets, a structure functionally analogous to a syringe needle, to deliver an array of secretions into the host plant tissue or cells. These stylet-delivered effector proteins in all likelihood require $\mathrm{N}$-terminal signal peptides that direct them to the secretory pathway of the esophageal gland cells. There, the signal peptide is cleaved off, resulting in the delivery of matured proteins into the host. The question of where exactly effector proteins are deposited (i.e., into the apoplast or directly into the host cell cytoplasm) remains somewhat unclear. Although deposition of certain nematode effector proteins during migration is clearly in the apoplast, a direct delivery into plant cells also appears likely. A number of recent reports documented intracellular localization of nematode effectors in the feeding cells but it has not been unequivocally determined whether these secretions are deposited externally to the plasma membrane and then taken up or deposited directly into the cytoplasm. However, unlike oomycete effector proteins, which contain RXLR motifs required for effector uptake into host cells (Birch et al. 2008), no common consensus signatures in any nematode effectors described to date have been identified that could function as uptake signals. Also, when assessing available video footage depicting the feeding behavior of cyst nematodes (Wyss and Zunke 1986), it is very tempting to postulate that appearance of the feeding tube in the cytoplasm of the feeding cells coincides with the secretory activity of the dorsal gland cell, thus strongly suggesting a direct deposition of stylet secretions into the host cell. Also, available micrographs of nematode stylets inserted into plant cells show an opening in the plant plasma membrane associated with the stylet orifice (Hussey et al. 1992; Sobczak et al. 1999). Furthermore, the ability of nematodes to take up fluorescent proteins from the feeding sites provides strong evidence that nematodes have direct access to the host cytoplasm (Boeckenhoff and Grundler 1994; Goverse et al. 1998; Urwin et al. 1997).

Following the deposition of effectors by the nematode through the stylet, the real question is where these proteins are ultimately performing their function, and these aspects become surprisingly complex. Characterizations of nematode effectors reported in the literature thus far provided evidence for extracellular and cytoplasmic as well as nuclear targeting, suggesting a wide range of functional activities of these proteins in the parasitized host cells. Although some effectors contain nuclear localization signals (NLS) that mediate protein targeting to the nucleus (Elling et al. 2007; Tytgat et al. 2004), other effectors most likely reach their final destination through the interaction with host factors that themselves are targeted to subcellular compartments. For example, cellulose binding protein (CBP), a beet cyst nematode effector shown to function in the cell wall, most likely accumulates first in the cytoplasm, from which it appears to be exported into the apoplast through its interaction with a host pectin methyl esterase protein (PME3) (Hewezi et al. 2008b). Similarly, Heterodera cyst nematode CLE peptides have been localized in the host cytoplasm, but the apoplast was shown to be the site of action of CLE peptides (Wang et al. 2010). Experimental evidence showed that the variable sequence domain N-terminal to the CLE motif acts as a targeting signal that directs the mature peptide to the apoplast (Wang et al. 2010), although the exact mechanism of this transport remains unknown.

Interestingly, two different mechanisms of translocation of other effector proteins inside host cells were elucidated. In one example, Heterodera cyst nematode effector 10A07 contains a functional NLS but, nonetheless, is mainly localized in the cytoplasm unless it can interact with a specific plant protein kinase, which mediates 10A07 translocation to the nucleus (Elling et al. 2007; T. Hewezi and T. J. Baum, unpublished data). Similarly, the ubiquitin extension protein from Heterodera schachtii (Hs-UBI1) was predicted to be localized in the cytoplasm, whereas the Hs-UBI1 C-terminal domain alone was found to be localized to the nucleolus in plant cells (Tytgat et al. 2004). In another intriguing example, the nuclear-localized Heterodera cyst nematode effector 32E03 was found to bind to host nuclear proteins, which apparently cause a translocation to nuclear bodies (Elling et al. 2007; T. Hewezi and T. J. Baum, unpublished data).

Protein tagging with fluorescent proteins has been widely used to localize pathogen effectors within plant cells to determine their sites of action. Tagging methods are valuable tools as long as the pathogen is amenable for genetic transformation. However, plant-parasitic nematodes are recalcitrant to such manipulations, making the detection of nematode effectors in the host cells a difficult challenge. Nevertheless, detection of nematode effector proteins in host cells and tissues has been shown in a number of cases using immunocytology (Doyle and Lambert 2002, 2003; Jaouannet et al. 2012; Jaubert et al. 2005; Vieira et al. 2011; Wang et al. 1999; Wang et al. 2010), demonstrating that the secretion of nematode effectors into host tissues during infection. The $\beta$-1,4-endoglucanase from $H$. glycines was the first nematode secretory protein to be localized in host plant tissues (Wang et al. 1999). $\beta$-1,4-Endoglucanase was localized along the nematode's migratory path through the root, confirming its site of action and function in cell wall degradation. Detection of cyst nematode CLE peptides inside host cytoplasm recently has been reported (Wang et al. 2010). In root-knot nematodes, pectate lyase and chorismate mutase from Meloidogyne javanica were localized outside of the nematode in the surrounding root tissues (Doyle and Lambert 2002, 2003). More recently, the secretion of five $M$. incognita effector proteins was detected in the apoplast of Arabidopsis roots during intercellular migration and giant-cell formation (Vieira et al. 2011). Several biological pieces of evidence suggested that effectors of root-knot nematodes are also localized inside host cells. The $M$. incognita $7 \mathrm{H} 08$ effector candidate contained a canonical NLS and was predicted to be targeted to the nucleus (Huang et al. 2003). In addition, the $M$. incognita $16 \mathrm{D} 10$ protein was shown to interact with plant transcription factors (Huang et al. 2006b). Finally, the secreted $M$. incognita EFF1 protein was found to be localized in the nuclei of giant cells using immunolocalization assays (Jaouannet et al. 2012).

\section{Functions of nematode effectors.}

The ever-increasing numbers of discovered pathogen effectors clearly underscore the important roles that these proteins play in mediating pathogen success. However, while ensuring infection success, it is the very same proteins that can elicit massive plant defense responses, which have to be overcome 
by the pathogen to mediate susceptibility. A comprehensive view of the multifaceted interactions between plants and pathogens is illustrated by the "zigzag" model described by Jones and Dangl (2006). In the first "zig", plants detect and perceive highly conserved pathogen molecules, so-called microbe-associated molecular patterns (MAMPs), and initiate an array of basal defense responses, the pattern-triggered immunity (PTI). Although no nematode MAMPs thus far have been identified, global gene expression analysis and symptoms associated with nematode infection such as the generation of reactive oxygen species (ROS), cell wall thickening, and callose deposition support the presence of nematode MAMPs and suggest that certain nematode secretions potentially could act as MAMPs. In the second step of the zigzag model, successful pathogens "zag" by acquiring the ability to overcome PTI by secreting multiple effectors that suppress PTI responses, resulting in effector-triggered susceptibility (ETS). In other words, in addition to secreting effectors that function in changing the host to allow parasitism (i.e., in the case of sedentary nematodes, induce the formation of feeding cells), a more or less large subset of effectors deals with the suppression of defense responses triggered by parasitism. As the next zig response, plants on the other hand have evolved multiple resistance $(R)$ genes that sense and recognize directly or indirectly the presence or activity of individual effectors and activate so called effector-triggered immunity (ETI). Under constant selective pressure, pathogens zag and acquire the ability to suppress ETI responses by altering the effector that is recognized by the plant or by acquiring new effectors. This, in turn, imposes further selective pressure on the plants to evolve new mechanisms to recognize the altered effectors or the newly acquired effectors, resulting again in ETI. Recent and ongoing functional characterization of nematode effectors revealed the function of some nematode effectors in mediating plant susceptibility or triggering defense response and allows first glimpses into this plant-pathogen interplay also for nematodes.

\section{Nematode effectors targeting host factors.}

Plant-parasitic nematodes manipulate host cellular processes to their benefit through specific interactions with certain host proteins. Yeast two-hybrid (Y2H) screens for potential host targets of nematode effectors have been particularly successful. Although only one Meloidogyne effector has been reported to have been successfully submitted to $\mathrm{Y} 2 \mathrm{H}$ analyses thus far, which identified Scarecrow-like plant transcription factors as being the target of the $M$. incognita 16D10 effector (Huang et al. 2006b), a number of successful projects have been reported for cyst nematode effectors. Such analyses revealed that nematode effectors target components of different cellular compartments and processes (Fig. 1). Arabidopsis PME3 (but not the PME1 and -2 homologs) has been shown to interact strongly and specifically with the $H$. schachtii CBP effector (Hewezi et al. 2008b). A 25-amino-acid-region of CBP was found to be essential and sufficient for recognition and binding of PME3. Effector 19C07 from $H$. schachtii was reported to interact with Arabidopsis auxin influx transporter LAX3 (Lee et al. 2011), raising the possibility that cyst nematodes directly target auxinmediated mechanisms, which have been shown to play critical roles in nematode-plant interactions. In other examples, the 10A06 Heterodera effector targets spermidine synthase 2 (SPDS2) of host plants, which documented altered polyamine signaling as a feature of cyst nematode parasitism (Hewezi et al. 2010). Heterodera effector 4F01 targets oxidoreductase, which is involved in plant defense and stress responses (Patel et al. 2010). Interestingly, the 4D09 and 19B10 Heterodera effectors both target plant 14.3 .3 proteins; however, from different clades, potentially demonstrating the requirement of nematodes to target redundant pathways in host cells (Maier et al. 2013). Another interesting finding that emerged from $\mathrm{Y} 2 \mathrm{H}$ screens is that cyst nematode effectors physically interact with different host protein kinases (Maier et al. 2013). Whether the nematode effectors interfere with kinase activity or whether this interaction is required for the virulence function of the effectors is currently unknown. Also, nematode effectors may directly interact with $\mathrm{R}$ proteins. This was demonstrated by the ability of the SPRY domain-containing proteins (SPRYSEC19) from Globodera rostochiensis to bind to a coiled-coil nucleotide-binding leucine-rich repeat (NB-LRR) (SW5-F) protein from susceptible tomato plants (Rehman et al. 2009). Although no evidence has been reported yet to suggest that SPRYSEC19 activates ETI in host plants, SPRYSEC-19 may bind to SW5-F to promote the virulence of the nematode by suppressing host defense responses (Rehman et al. 2009). Recently, it has been shown that the VAP1 effector from $G$. rostochiensis binds to tomato cysteine protease Rcr $3^{\text {pim }}$ and perturbs its active site, thereby increasing plant susceptibility to the nematode (Lozano-Torres et al. 2012).

\section{Nematode ETS.}

Although, in a narrow sense, ETS refers to the suppression of host defenses by pathogen effector functions, in a wider sense, any increase in susceptibility due to effector functions may be considered under this definition as well. Strong evidence for the involvement of cyst nematode effectors in promoting host susceptibility to nematode infection was provided through overexpression analyses (Fig. 1). The Heterodera cyst nematode effectors $C B P, 10 A 06,4 F 01$, and $30 C 02$ increased nematode susceptibility when overexpressed in Arabidopsis (Hamamouch et al. 2012; Hewezi et al. 2008b, 2010; Patel et al. 2010). Genetic and biochemical studies indicated that the role of CBP in promoting host susceptibility is mainly due to its association with PME3 in host cells. CBP increases PME3 activity, thereby reducing the level of methylesterified pectin in cell walls and, subsequently, facilitating the access of other cell-wall-modifying enzymes to cell wall polymers, which is required for syncytium formation and development. In support, $P M E 3$ overexpression lines, like $C B P$ overexpression, showed elevated susceptibility to cyst nematodes, whereas $P M E 3$ knockout mutants exhibited the opposite phenotype of reduced susceptibility. Expression of $C B P$ in the pme3 knockout mutant revealed that PME3 is required but not the sole factor responsible for the elevated susceptibility phenotype in the $C B P$ expressing plants (Hewezi et al. 2008b).

The contributions of 10A06 and 4F01 to promoting nematode parasitism of host plants seem to be mediated through manipulating host basal defense responses and reducing stress reactions, respectively. 10A06 binds to and activates SPDS2, a key enzyme involved in polyamine biosynthesis. Transgenic plants expressing $10 A 06$ exhibited elevated spermidine content and increased polyamine oxidase (PAO) activity, supporting the 10A06/SPDS2 association in planta (Hewezi et al. 2010). The subsequent degradation of spermidine through PAO stimulates the induction of the plant antioxidant machinery, which likely protects the nematode feeding structure and the nematode from ROS that are triggered during infection as a common response of host plants to nematode infection, potentially mediated through nematode MAMPs. Also, constitutive expression of 10A06 resulted in increased susceptibility to other plant pathogens, suggesting the interference of this effector with basal defense responses by repression of salicylic acid signaling, as shown by the downregulation of pathogenesis-related $(P R)$ genes $P R 1, P R 2$, and $P R 5$ in 10A06-expressing plants.

The 4F01 annexin-like effector from $H$. schachtii was shown to functionally complement Arabidopsis annexin mutant AnnAt1 


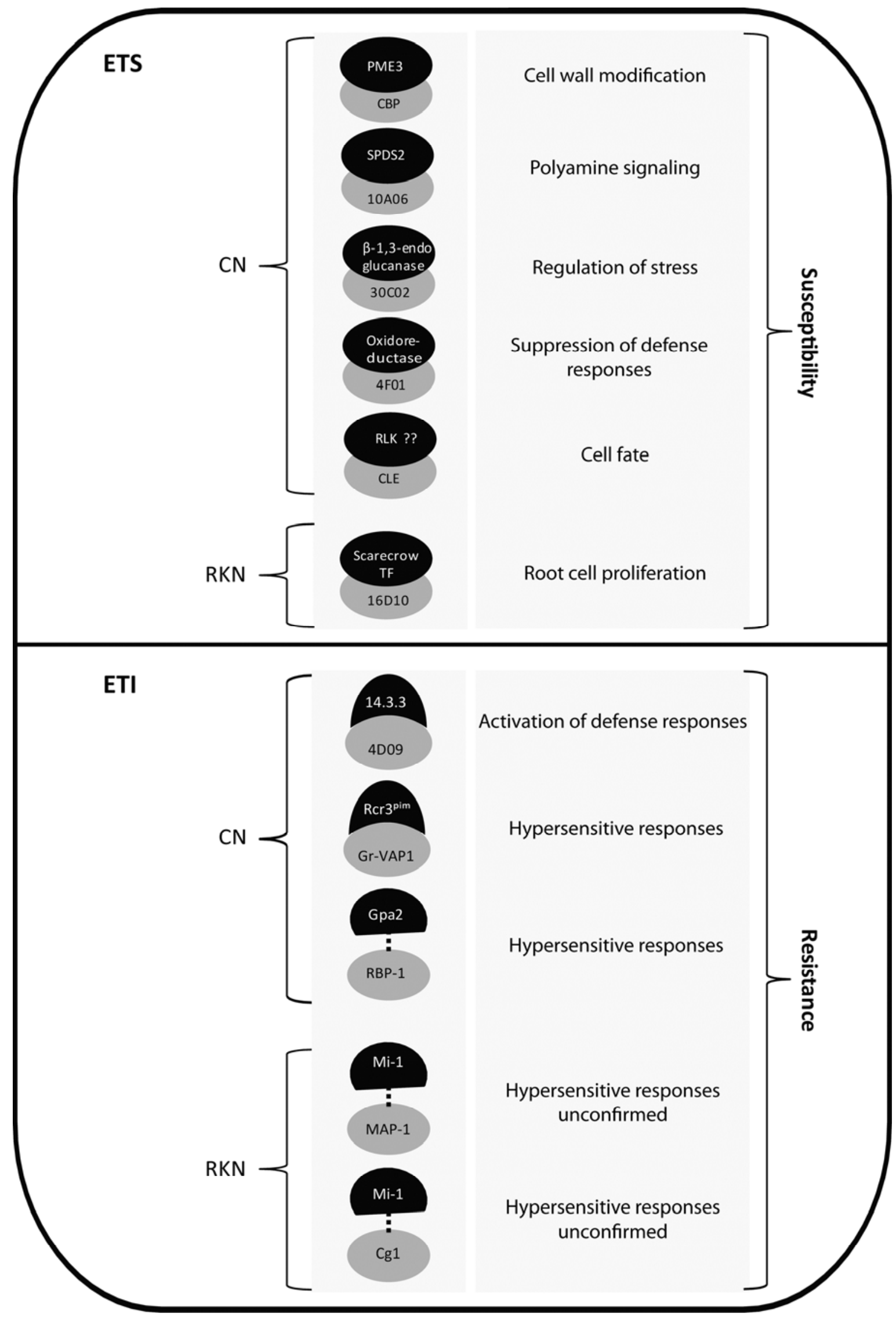

Fig. 1. Interactions between cyst nematode $(\mathrm{CN})$ and root-knot-nematode $(\mathrm{RKN})$ effector proteins and their host targets. Upper panel: effector-triggered susceptibility (ETS); effectors of CN and RKN interact with host proteins with different biological functions to facilitate disease. Lower panel: effectortriggered immunity (ETI); nematode effectors can directly or indirectly interact with host factors to activate defense signaling or hypersensitive responses leading to resistance. Nematode effectors and host interacting proteins are represented in gray and black, respectively. Dotted lines indicate indirect interactions. $\mathrm{TF}=$ transcription factor and $\mathrm{RLK}=$ receptor-like kinases. 
(Patel et al. 2010), suggesting that 4F01 may mimic host annexin function in regulating stress responses during infection. 4F01 increased nematode susceptibility upon constitutive expression in Arabidopsis. Consistent with its role in stress response, 4F01 was found to interact with an Arabidopsis oxidoreductase member of the 2OG-Fe(II) oxygenase family. The interaction of $4 \mathrm{~F} 01$ with plant oxidoreductase could be a strategy deployed by the nematode to prevent activation of defense gene expression mediated by plant oxidoreductase. However, further experiments are required to test this hypothesis. Another example demonstrating the suppression of host defense by a nematode effector was provided through the functional characterization of Heterodera cyst nematode effector 30C02 (Hamamouch et al. 2012). Expression of $30 \mathrm{CO} 2$ in Arabidopsis significantly increased plant susceptibility to $H$. schachtii. Unlike 10A06, the expression of 30C02 did not impact the expression of $P R$ genes but, rather, the effector directly targeted a specific plant PR protein: namely, $\beta$-1,3-endoglucanase. In contrast to $30 \mathrm{CO} 2$ overexpression, $\beta$-1,3-endoglucanase overexpression in Arabidopsis produced plants that were less susceptible to infection by $H$. schachtii, whereas the $\beta$-1,3-endoglucanase T-DNA knockout line exhibited the opposite phenotype of increased susceptibility, indicating that $30 \mathrm{C} 02$ acts in suppressing $\beta$-1,3-endoglucanase activity to promote parasitism.

The ability to inactivate effector genes in the nematode via host-derived RNAi and assess possible effects on parasitic success has provided further insights into the contribution of nematode effectors toward pathogenicity. The validity of this approach was first demonstrated with the M. incognita $16 \mathrm{D} 10$ gene, which encodes a 13-amino-acid secreted peptide. Transgenic Arabidopsis plants engineered to produce small RNA targeting the $16 D 10$ gene exhibited substantial resistance against the four major root-knot nematode species (Huang et al. 2006a), demonstrating an essential role of the 16D10 peptide in root-knot nematode parasitism. Host-derived RNAi approaches were also shown to function against cyst nematode effector genes $C B P, 10 A 06,4 F 01$, and 30C02, and negatively impacted parasitic success to varying extents (Hamamouch et al. 2012; Patel et al. 2008, 2010; Sindhu et al. 2009).

\section{Nematode ETI.}

Effectors that reduce nematode parasitism and increase plant resistance have also been described and, thus, fit the definition of ETI in the widest sense, although a direct involvement of a stereotypical $R$ gene is frequently missing. For example, constitutive expression of $H$. schachtii 4D09 in Arabidopsis led to significant decreases in nematode susceptibility (Fig. 1). 4D09 binds to $14-3-3 \varepsilon$ and directly or indirectly controls the expression of a set of genes with functions in basal defense responses (Maier et al. 2013). Importantly, 4D09 was not able to activate basal defense responses when overexpressed in the absence of $14-3-3 \varepsilon$ and produced plants with susceptibility to nematode infection similar to that of wild-type plants.

In a more canonical ETI example, the effector protein RBP-1 from the potato cyst nematode G. pallida was reported to elicit defense responses, including cell death characteristic of a hypersensitive response (HR), through the NB-LRR protein Gpa2 (Sacco et al. 2009) (Fig. 1). Root-knot nematode MAP-1 is another effector with functions related to ETI (Fig. 1). MAP-1 was identified through differential molecular analyses of virulent and avirulent near-isogenic lines of $M$. incognita selected on plants containing the $M i-1$ resistance gene (Semblat et al. 2001). The MAP-1 proteins contain highly conserved repeats, and variation in the number and arrangement of these repeats is correlated with nematode avirulence (Castagnone-Sereno et al. 2009). However, the role of MAP-1 in triggering immune response in conjunction with the Mi-1 resistance protein needs to be demon- strated. Similarly, $\mathrm{Cg} 1$ from $M$. javanica also appears to be involved in triggering immune response in host plants carrying the Mi-1 resistance gene (Gleason et al. 2008) (Fig. 1). Continued culturing of an avirulent $M$. javanica strain on resistant tomato resulted in the loss of $C g l$ and gave rise to a virulent strain that is able to reproduce on tomato plants carrying the $M i-1$ resistance gene. Silencing the $C g l$ gene in the avirulent strain by RNAi conferred virulence to this strain, thus implying a role of Cgl in triggering Mi-1-mediated resistance. The mechanism by which $\mathrm{Cg} 1$ directly or indirectly interacts with the Mi-1 protein is currently unknown and requires further studies. As mentioned above, the $G$. rostochiensis effector VAP1 was found to interact with the apoplastic cysteine protease $\mathrm{Rcr} 3^{\text {pim }}$ from tomato (Lozano-Torres et al. 2012). Rcr3 ${ }^{\text {pim }}$ is guarded by the tomato Cf-2 resistance protein, and Rcr3 ${ }^{\text {im }}$ perturbations during Cladosporium fulvum infection have been shown to elicit hypersensitive resistance against this fungal pathogen (Krüger et al. 2002; Rooney et al. 2005) Although, in the absence of Cf-2, VAP1 increases plant susceptibility, in tomato plants expressing $C f-2$ and $R c r 3^{\text {pim }}$, VAP-1 triggers defense-related programmed cell death in host cells (Lozano-Torres et al. 2012) and, therefore, exhibits a stereotypical ETI phenotype (Fig. 1).

\section{Effector functions and root developmental changes.}

As mentioned above, nematode effectors are engaged in developmental pathways that mediate the transition of the targeted cells into metabolically active sinks. As a result of this engagement, host roots are severely altered. Roots infected with cyst nematodes are often dwarfed and develop frequent branching, whereas roots infected with root-knot nematodes are stubby and galled. Even more obvious, individual root cells developing into feeding cells are grossly altered in their appearance and physiology The identification of host proteins interacting with nematode effectors made it possible to connect root morphological alterations with host factor recognition and functions. In one example, this was accomplished by comparing the effects of $H$. schachtii 10A06 (Hs-10A06) and its orthologous sequence from $H$. glycines $(\mathrm{Hg}-10 \mathrm{~A} 06)$ on root development in Arabidopsis. Although Hs-10A06 and Arabidopsis SPDS2 interact strongly and specifically, $\mathrm{Hg}-10 \mathrm{~A} 06$ binds to Arabidopsis SPDS2 at a much lower level. Consistent with this difference in binding affinity, constitutive expression of $\mathrm{Hs}_{\text {- }}$ $10 A 06$ in Arabidopsis produced plants with significantly increased root lengths (Hewezi et al. 2010), whereas expression of $\mathrm{Hg}-10 \mathrm{AOC}$ in Arabidopsis affected root length to a much lesser extent (Hewezi and Baum 2010). The impact of SPDS2 and polyamine signaling on root emergence, formation, and development has been reported in various plant species (Bais and Ravishankar 2002; Kakkar et al. 2000), which makes it likely that, in fact, effector-mediated alterations of SPDS2 and polyamines are responsible for the different Arabidopsis root morphology changes during $\mathrm{Hs}$ - and $\mathrm{Hg}-10 \mathrm{AOO}$ overexpression. The function of pectin methylesterification in regulating the physiochemical properties of the cell wall, thereby affecting cell separation and elongation, has been explored comprehensively (Wolf et al. 2009). The long-root phenotype reported in $C B P$-expressing plants is most likely due to the increased activity of PME3 in these plants (Hewezi et al. 2008b). Consistent with previous reports (Wen et al. 1999), increasing PME3 activity produces plants with longer roots, whereas inhibiting this activity negatively impacts root development (Hewezi et al. 2008b). Intriguingly, the increased root length of $C B P$-expressing plants was not associated with larger syncytium size, suggesting that the developmental program formation is independent of those of root development.

The known examples of nematode effectors resembling plant signaling peptides (cyst nematode CLE-like effectors and 
the root-knot $16 \mathrm{D} 10$ proteins) were also found to interfere with correct cell fate specification required for root development. The implication of cyst nematode CLE-like effectors in root growth and differentiation was extensively shown through in planta overexpression assays or in vitro by exogenous application of synthetic 12-amino-acid peptides corresponding to the CLE motif (Gheysen and Mitchum 2011; Mitchum et al. 2008). Although CLE signaling and downstream components that mediate root development changes are unknown, they seem to include the receptor kinase family members CORYNE and CLAVATA 2 (Replogle et al. 2011) (Fig. 1). Similarly, the 16D10 signaling peptide from $M$. incognita was found to stimulate root growth when overexpressed in Arabidopsis (Huang et al. 2006b). 16D10 was shown to interact with tomato Scarecrow-like transcription factors (Huang et al. 2006b) (Fig. 1), which regulate root radial pattering (Pysh et al. 1999). These findings demonstrate that the secreted nematode peptide functions as a signaling molecule to interfere with root proliferation by specifically targeting host transcription factors.

Manipulation of auxin signaling through nematode effectors could contribute to root developmental changes. The interaction of cyst nematode effector 19C07 with LAX3, a key factor promoting lateral root emergence (Swarup et al. 2008), seems to be the mode of action responsible for increasing lateral root formation in the 19C07-expressing plants (Lee et al. 2011). In another study, overexpression of chorismate mutase from $M$. javanica in soybean hairy roots produced an auxin-deficiency phenotype of reduced and aborted lateral roots (Doyle and Lambert 2003). This phenotype was rescued by the exogenous addition of indole-3-acetic acid (IAA), suggesting that chorismate mutase inhibits IAA biosynthesis.

\section{Root size does not matter.}

The frequent impact of nematode effectors on root development upon overexpression in host plants raised the question of whether altered susceptibility observed in the transgenic lines was a specific result of the effector's function or simply an unspecific consequence of the increased or reduced root area available for penetrating nematodes. Several experimental lines of evidence point out that the mode of action responsible for changes in nematode susceptibility and syncytium size in the transgenic plants expressing nematode effectors is independent of root length or mass over a wide range of root sizes. For example, mutant lines with root systems that are approximately one-third to one-half the size of wild-type plants were found to be more susceptible to cyst nematode than the wild type (Wubben et al. 2001; T. Hewezi and T. J. Baum, unpublished data) whereas, in other cases, increasing root length was not always associated with increasing nematode susceptibility. In addition, no significant differences were detected between the size of syncytia from mutant lines producing longer or shorter roots and those of the wild type (Hewezi et al. 2008b; Jin et al. 2011). Furthermore, another indication that root size does not alter plant susceptibility over a wide range is the observation that the number of penetrating $\mathrm{J} 2$ nematodes in transgenic plants developing long- or short-root phenotypes is similar (Hewezi et al. 2008b, 2012).

\section{Perspectives and future directions.}

i) The rapid progress of sequencing technology in the recent past revolutionized the field of molecular plant pathology and enabled the identification of candidate effector genes at genome levels in a wide range of plant pathogens. Because the majority of these effectors are without sequence homology to proteins with known functions, the continuous challenge will be to determine the contribution of these effectors to parasitism. Much emphasis is currently given to identifying host factors interact- ing with nematode effectors because this will lead to the discovery of mechanisms by which these effectors influence parasitism. Continued functional characterization of nematode effectors could lead to the identification of those effectors acting as avirulence factors, thus facilitating the identification and exploitation of the requisite resistance genes for durable nematode resistance.

ii) It seems likely that parasitic nematodes manipulate developmental pathways and defense signaling that are under the control of microRNAs (miRNAs) (Hewezi et al. 2008a; 2012). How nematode effectors manipulate the expression and the function of miRNA genes for successful parasitism is a challenging question. Taking into consideration that miRNAs are conserved across plant species, answering this question could lead to the uncovering of common signaling networks and developmental pathways in host plants targeted by various parasitic nematodes.

iii) With the fast progress in easily identifying and isolating esophageal gland cells from phytonematodes, it should soon be possible to compare the parasitome of different strains with different virulence phenotypes and then correlate polymorphisms in effector genes with specific virulence or avirulence functions. In this context, several nematode effectors belong to gene families and exhibit high rates of amino acid polymorphisms, specifically outside of the signal peptide region. With the availability of complete parasitomes, it will be possible to calculate the rates of nonsynonymous and synonymous mutations across all members of any given nematode gene to determine the selection pressures causing sequence diversification and determine the role of positive diversifying selection in nematode virulence.

iv) Currently, the whole-genome sequences of two phytonematodes, M. incognita and M. hapla (Abad et al. 2008; Opperman et al. 2008), are available. In addition, the sequences of the complete genomes of several additional phytonematodes, including $H$. glycines, $G$. pallida, G. rostochiensis, $M$. arenaria, $M$. javanica, and $M$. chitwoodi, should be available in the near future. These data will provide enormous opportunities to identify the complete suite of genetic determinants responsible for parasitism. Comparative genomic analyses across nematode species will provide information relevant to understanding the mode of infection and the evolution of host range of these phytonematodes. Comparative genomic analyses will also reveal the contributions of horizontal gene transfer (HGT) to parasitism. For example, several effector genes, specifically those with cell-wall-related functions, seem to be acquired by multiple HGT events (Danchin et al. 2010; Smant et al. 1998). These genes are normally organized in variable genomic regions, which can be identified through differences in GC contents compared with the core genome regions, enrichment of mobile elements, and absence of a syntenic orthologs in closely related genomes. Comparing these regions among nematode genomes would shed light onto the diversity and the evolutionary origin of effector repertoires. Genome sequences will also help in identifying promoter regulatory elements that ensure synchronized expression of nematode effector genes in the different esophageal gland cells. Effectors synthesized in the two subventral gland cells and those produced in the dorsal gland cells likely have different promoter sequence signatures to ensure coordinated expression during distinct stages of parasitism, and genomic analyses will allow identification of specific conserved motifs.

\section{ACKNOWLEDGMENTS}

We thank all current and past members of the Baum laboratory and our collaborators and fellow scientists researching the mechanisms of nema- 
tode parasitism for their invaluable contributions; and the United States Department of Agriculture National Research Initiative and Agriculture and Food Research Initiative, the National Science Foundation, and soybean grower associations for funding our research visions.

\section{LITERATURE CITED}

Abad, P., Gouzy, J., Aury, J.-M., Castagnone-Sereno, P., Danchin, E. G. J., Deleury, E., Perfus Barbeoch, L., Anthouard, V., Artiguenave, F., Blok, V. C., Caillaud, M.-C., Coutinho, P. M., Dasilva, C., De Luca, F., Deau, F., Esquibet, M., Flutre, T., Goldstone, J. V., Hamamouch, N., Hewezi, T., Jaillon, O., Jubin, C., Leonetti, P., Magliano, M., Maier, T. R., Markov, G. V., McVeigh, P., Pesole, G., Poulain, J., Robinson-Rechavi, M., Sallet, E., Segurens, B., Steinbach, D., Tytgat, T., Ugarte, E., van Ghelder, C., Veronico, P., Baum, T. J., Blaxter, M., Bleve-Zacheo, T., Davis, E. L., Ewbank, J. J., Favery, B., Grenier, E., Henrissat, B., Jones, J. T., Laudet, V., Maule, A. G., Quesneville, H., Rosso, M.-N., Schiex, T., Smant, G., Weissenbach, J., and Wincker, P. 2008. Genome sequence of the metazoan plant-parasitic nematode Meloidogyne incognita. Nat. Biotechnol. 26:909-915.

Bais, H. P., and Ravishankar, G. A. 2002. Role of polyamines in the ontogeny of plants and their biotechnological applications. Plant Cell Tiss. Org. 69:1-34.

Birch, P. R., Boevink, P. C., Gilroy, E. M., Hein, I., Pritchard, L., and Whisson, S. C. 2008. Oomycete RXLR effectors: Delivery, functional redundancy and durable disease resistance. Curr. Opin. Plant Biol. $11: 373-379$

Böckenhoff, A., and Grundler, F. M. W. 1994. Studies on the nutrient uptake by the beet cyst nematode Heterodera schachtii by in situ microinjection of fluorescent probes into the feeding structures in Arabidopsis thaliana. Parasitology 109:249-254.

Castagnone-Sereno, P., Semblat, J. P., and Castagnone, C. 2009. Modular architecture and evolution of the map-1 gene family in the root-knot nematode Meloidogyne incognita. Mol. Genet. Genomics 282:547-554.

Danchin, E. G., Rosso, M. N., Vieira, P., de Almeida-Engle, J., Coutinho, P. M., Henrissat, B., and Abad, P. 2010. Multiple lateral gene transfers and duplications have promoted plant parasitism ability in nematodes. Proc. Natl. Acad. Sci. U.S.A. 107:17651-17656.

Davis, E. L., Hussey, R. S., and Baum, T. J. 2004. Getting to the roots of parasitism by nematodes. Trends Parasitol. 20:134-141.

Davis, E. L., Hussey, R. S., Mitchum, M. G., and Baum, T. J. 2008. Parasitism proteins in nematode-plant interactions. Curr. Opin. Plant Biol. $11: 360-366$

Doyle, E. A., and Lambert, K. N. 2002. Cloning and characterization of an esophageal-gland-specific pectate lyase from the root-knot nematode Meloidogyne javanica. Mol. Plant-Microbe Interact. 15:549-556.

Doyle, E. A., and Lambert, K. N. 2003. Meloidogyne javanica chorismate mutase 1 alters plant cell development. Mol. Plant-Microbe Interact. $16: 123-131$

Elling, A. A., Davis, E. L., Hussey, R. S., and Baum, T. J. 2007. Active uptake of cyst nematode parasitism proteins into the plant cell nucleus. Int. J. Parasitol. 37:1269-1279.

Gheysen, G., and Mitchum, M. G. 2011. How nematodes manipulate plant development pathways for infection. Curr. Opin. Plant Biol. 14:415-421

Gleason, C. A., Liu, Q. L., and Williamson, V. M. 2008. Silencing a candidate nematode effector gene corresponding to the tomato resistance gene Mi-1 leads to acquisition of virulence. Mol. Plant-Microbe Interact. 21:576-585.

Goverse, A., Biesheuvel, J., Wijers, G. J., Gommers, F. J., Bakker, J., Schots, A., and Helder, J. 1998. In planta monitoring of the activity of two constitutive promoters, CaMV $35 \mathrm{~S}$ and TR2', in developing feeding cells induced by Globodera rostochiensis using green fluorescent protein in combination with confocal laser scanning microscopy. Physiol. Mol. Plant Pathol. 52:275-284.

Hamamouch, N., Li, C., Hewezi, T., Baum, T. J., Mitchum, M. G., Hussey, R. S., Vodkin, L. O., and Davis, E. L. 2012. The interaction of the novel $30 \mathrm{C} 02$ cyst nematode effector protein with a plant $\beta-1,3$-endoglucanase may suppress host defence to promote parasitism. J. Exp. Bot. Online publication. doi:10.1093/jxb/ers058

Hewezi, T., and Baum, T. J. 2010. Sequence divergences between cyst nematode effector protein orthologs may contribute to host specificity. Plant Signal. Behav. 5:187-189.

Hewezi, T., Howe, P., Maier, T. R., and Baum, T. J. 2008a. Arabidopsis small RNAs and their targets during cyst nematode parasitism. Mol. Plant-Microbe Interact. 21:1622-1634.

Hewezi, T., Howe, P., Maier, T. R., Hussey, R. S., Mitchum, M. G., Davis, E. L., and Baum, T. J. 2008b. Cellulose binding protein from the parasitic nematode Heterodera schachtii interacts with Arabidopsis pectin methylesterase: Cooperative cell wall modification during parasitism.
Plant Cell 20:3080-3093.

Hewezi, T., Howe, P. J., Maier, T. R., Hussey, R. S., Mitchum, M. G., Davis, E. L., and Baum, T. J. 2010. Arabidopsis spermidine synthase is targeted by an effector protein of the cyst nematode Heterodera schachtii. Plant Physiol. 152:968-984.

Hewezi, T., Maier, T., Nettleton, D., and Baum T. J. 2012. Arabidopsis microRNA396-GRF1/GRF3 regulatory module acts as a developmental regulator in the reprogramming of root cells during cyst nematode infection. Plant Physiol. 159:321-335.

Hogenhout, S. A., Van der Hoorn, R. A., Terauchi, R., and Kamoun, S. 2009. Emerging concepts in effector biology of plant-associated organisms. Mol. Plant-Microbe Interact. 22:115-122.

Huang, G., Gao, B., Maier, T., Allen, R., Davis, E. L., Baum, T. J., and Hussey. R. S. 2003. A profile of putative parasitism genes expressed in the esophageal gland cells of the root-knot nematode Meloidogyne incognita. Mol. Plant-Microbe Interact. 16:376-381.

Huang, G., Allen, R., Davis, E. L., Baum, T. J., and Hussey, R. S. 2006a. Engineering broad root-knot resistance in transgenic plants by RNAi silencing of a conserved and essential root-knot nematode parasitism gene. Proc. Natl. Acad. Sci. U.S.A. 103:14302-14306.

Huang, G., Dong, R., Allen, R., Davis, E. L., Baum, T. J., and Hussey, R. S. 2006b. A root-knot nematode secretory peptide functions as a ligand for a plant transcription factor. Mol. Plant-Microbe Interact. 19:463470.

Hussey, R. S. 1989. Disease-inducing secretions of plant parasitic nematodes. Annu. Rev. Phytopathol. 27:123-141.

Hussey, R. S., and Mims C. W. 1990. Ultrastructure of esophageal glands and their secretory granules in the root-knot nematode Meloidogyne incognita. Protoplasma 156:9-18.

Hussey, R. S., Mims, C. W., and Westcott, S. W. 1992. Ultrastructure of root cortical cells parasitized by the ring nematode Criconemella xenoplax. Protoplasma 167:55-65.

Jaouannet, M., Perfus-Barbeoch, L., Deleury, E., Magliano, M., Engler, G., Vieira, P., Danchin, E. G., Rocha, M. D., Coquillard, P., Abad, P., and Rosso, M. N. 2012. A root-knot nematode-secreted protein is injected into giant cells and targeted to the nuclei. New Phytol. 194:924931.

Jaubert, S., Milac, A. L., Petrescu, A. J., de Almeida-Engler, J., Abad, P., and Rosso, M. N. 2005. In planta secretion of a calreticulin by migratory and sedentary stages of root-knot nematode. Mol. Plant-Microbe Interact. 18:1277-1284.

Jin, J., Hewezi, T., and Baum, T. J. 2011. The Arabidopsis bHLH25 and bHLH27 transcription factors contribute to susceptibility to the cyst nematode Heterodera schachtii. Plant J. 65:319-328.

Jones, J. D., and Dangl, J. L. 2006. The plant immune system. Nature 444:323-329

Kakkar, R. K., Nagar, P. K., Ahuja, P. S., and Rai, V. K. 2000. Polyamines and plant morphogenesis. Biol. Plant 43:1-11.

Krüger, J., Thomas, C. M., Golstein, C., Dixon, M. S., Smoker, M., Tang, S., Mulder, L., and Jones, J. D. 2002. A tomato cysteine protease required for Cf-2-dependent disease resistance and suppression of autonecrosis. Science 296:744-747.

Lee, C., Chronis, D., Kenning, C., Peret, B., Hewezi, T., Davis, E. L., Baum, T. J., Hussey, R., Bennett, M., and Mitchum, M. G. 2011. The novel cyst nematode effector protein 19C07 interacts with the Arabidopsis auxin influx transporter LAX3 to control feeding site development. Plant Physiol. 155:866-880.

Lozano-Torres J. L., Wilbers, R. H., Gawronski, P., Boshoven, J. C., Finkers-Tomczak, A., Cordewener, J. H., America, A. H., Overmars, H. A., Van't Klooster, J. W., Baranowski, L., Sobczak, M., Ilyas, M., van der Hoorn, R. A., Schots, A., de Wit, P. J., Bakker, J., Goverse, A., and Smant, G. 2012. Dual disease resistance mediated by the immune receptor Cf-2 in tomato requires a common virulence target of a fungus and a nematode. Proc. Natl. Acad. Sci. U.S.A. 109:10119-10124.

Maier, T. R., Hewezi, T., Peng, J., and Baum, T. J. 2013. Isolation of whole esophageal gland cells from plant-parasitic nematodes for transcriptome analyses and effector identification. Mol. Plant-Microbe Interact. 13:3135 .

Mitchum, M. G., Wang, X., and Davis, E. L. 2008. Diverse and conserved roles of CLE peptides. Curr. Opin. Plant Biol. 11:75-81.

Opperman, C. H., Bird, D. M., Williamson, V. M., Rokhsar, D. S., Burke, M., Cohn, J., Cromer, J., Diener, S., Gajan, J., Graham, S., Houfek, T. D., Liu, Q., Mitros, T., Schaff, J., Schaffer, R., Scholl, E., Sosinski, B. R., Thomas, V. P., and Windham, E. 2008. Sequence and genetic map of Meloidogyne hapla: A compact nematode genome for plant parasitism. Proc. Natl. Acad. Sci. U.S.A. 105:14802-14807.

Patel, N., Hamamouch, N., Chunying, L., Hussey, R., Mitchum, M., Baum, T., Wang, X., and Davis, E. L. 2008. Similarity and functional analyses of expressed parasitism genes in Heterodera schachtii and Heterodera glycines. J. Nematol. 40:299-310. 
Patel, N., Hamamouch, N., Li, C., Hewezi, T., Hussey, R. S., Baum, T. J., Mitchum, M. G., and Davis, E. L. 2010. A nematode effector protein similar to annexins in host plants. J. Exp. Bot. 61:235-248.

Perry, R. N. 1996. Chemoreception in plant-parasitic nematodes. Annu. Rev. Phytopathol. 34:181-199.

Pysh, L. D., Wysocka-Diller, J. W., Camilleri, C., Bouchez, D., and Benfey, P. N. 1999. The GRAS gene family in Arabidopsis: Sequence characterization and basic expression analysis of the SCARECROWLIKE genes. Plant J. 18:111-119.

Rehman, S., Postma, W., Tytgat, T., Prins, P., Qin, L., Overmars, H., Vossen, J., Spiridon, L. N., Petrescu, A. J., Goverse, A, Bakker, J., and Smant, G. 2009. A secreted SPRY domain-containing protein (SPRYSEC) from the plant-parasitic nematode Globodera rostochiensis interacts with a CC-NB-LRR protein from a susceptible tomato. Mol. Plant-Microbe Interact. 22:330-340.

Replogl, A., Wang J., Bleckmann A., Hussey R. S., Baum T. J. Shinichiro S., Davis E. L., Wang, X., Simon, R., and Mitchum M. G. 2011. Nematode CLE signaling in Arabidopsis requires CLAVATA2 and CORYNE. Plant J. 65:430-440.

Rooney, H. C., Van't Klooster, J. W., van der Hoorn, R. A., Joosten, M. H., Jones, J. D., and de Wit, P. J. 2005. Cladosporium Avr2 inhibits tomato Rcr3 protease required for Cf-2-dependent disease resistance. Science 308:1783-1786.

Sacco, M. A., Koropacka, K., Grenier, E., Jaubert, M. J., Blanchard, A., Goverse, A., Smant, G., and Moffett, P. 2009. The cyst nematode SPRYSEC protein RBP-1 elicits Gpa2- and RanGAP2-dependent plant cell death. PLoS Pathog. 5:e1000564.

Semblat, J. P., Rosso, M. N., Hussey, R. S., Abad, P., and CastagnoneSereno P. 2001. Molecular cloning of a cDNA encoding an amphidsecreted putative avirulence protein from the root-knot nematode Meloidogyne incognita. Mol. Plant-Microbe Interact. 14:72-79.

Sindhu, A. S., Maier, T. R., Mitchum, M. G., Hussey, R. S., Davis, E. L. and Baum, T. J. 2009. Effective and specific in planta RNAi in cyst nematodes: Expression interference of four parasitism genes reduces parasitic success. J. Exp. Bot. 60:315-324.

Smant, G., Stokkermans, J., Yan, Y., de Boer, J. M., Baum, T., Wang, X. Hussey, R. S., Davis, E. L., Gommers, F. J., Henrissat, B., Helder, J., Schots, A., and Bakker, J. 1998. Endogenous cellulases in animals: Cloning of expressed $\beta-1,4$-endoglucanase genes from two species of plantparasitic cyst nematodes. Proc. Natl. Acad. Sci. U.S.A. 95:4906-4911.

Sobczak, M., Golinowski, W., and Grundler, F. M. W. 1999. Ultrastructure of feeding plugs and feeding tubes formed by Heterodera schachtii. Nematology 1:363-374.

Swarup, K., Benková, E., Swarup, R., Casimiro, I., Péret, B., Yang, Y., Parry, G., Nielsen, E., De Smet, I., Vanneste, S, Levesque, M. P., Carrier, D., James, N., Calvo, V., Ljung, K., Kramer, E., Roberts, R., Graham, N., Marillonnet, S., Patel, K., Jones, J. D. G., Taylor, C. G., Schachtman, D. P., Sandberg, G., Benfey, P., Friml, J., Kerr, I., Beeckman, T., Laplaze, L., and Bennett, M. J. 2008. The auxin influx carrier LAX3 promotes lateral root emergence. Nat. Cell Biol. 10:946-954.

Tytgat, T., Vanholme, B., De Meutter, J., Claeys, M., Couvreur, M., Vanhoutte, I., Gheysen, G., Van Criekinge, W., Borgonie, G., Coomans, A., and Gheysen, G. 2004. A new class of ubiquitin extension proteins secreted by the dorsal pharyngeal gland in plant parasitic cyst nematodes. Mol. Plant-Microbe Interact. 17:846-852.

Urwin, P. E, Møller, S. G., Lilley, C. J., McPherson, M. J., and Atkinson, H. J. 1997. Continual green-fluorescent protein monitoring of cauliflower mosaic virus 35S promoter activity in nematode-induced feeding cells in Arabidopsis thaliana. Mol. Plant-Microbe Interact. 10:394-400.

Vieira, P., Danchin, E. G., Neveu, C., Crozat, C., Jaubert, S., Hussey, R. S., Engler, G., Abad, P., de Almeida-Engler, J., Castagnone-Sereno, P., and Rosso, M. N. 2011. The plant apoplasm is an important recipient compartment for nematode secreted proteins. J. Exp. Bot. 62:1241-1253.

Wang, J., Lee, C., Replogle, A., Joshi, S., Korkin, D., Hussey, R., Baum, T. J., Davis, E. L., Wang, X., and Mitchum, M. G. 2010. Dual roles for the variable domain in protein trafficking and host-specific recognition of Heterodera glycines CLE effector proteins. New Phytol. 187:10031017

Wang, X., Meyers, D., Yan, Y., Baum, T., Smant, G., Hussey, R., and Davis, E. L. 1999. In planta localization of a $\beta-1,4-$ endoglucanase secreted by Heterodera glycines. Mol. Plant-Microbe Interact. 12:64-67.

Wen, F., Zhu, Y., and Hawes, M. C. 1999. Effect of pectin methyl-esterase gene expression on pea root development. Plant Cell 11:1129-1140.

Wolf, S., Mouille, G., and Pelloux, J. 2009. Homogalacturonan methylesterification and plant development. Mol. Plant 2:851-860.

Wubben, M. J. E., II, Su, H., Rodermel, S. R., and Baum, T. J. 2001. Susceptibility to the sugar beet cyst nematode is modulated by ethylene signal transduction in Arabidopsis thaliana. Mol. Plant-Microbe Interact. 14:1206-1212.

Wyss, U., and Zunke, U. 1986. Observations on the behaviour of second stage juveniles of Heterodera schachtii inside host roots. Rev. Nematol. 9:153-165. 